\title{
Cognition in a multiple system atrophy series of cases from Argentina
}

\author{
Cognição em uma série dos casos de atrofia de múltiplos sistemas da Argentina \\ Emilia Gatto ${ }^{1,2}$, Ignacio Demey ${ }^{3}$, Ana Sanguinetti ${ }^{1}$, Virginia Parisi ${ }^{2}$, José Luis Etcheverry ${ }^{1}$, Galeno Rojas ${ }^{3}$, \\ Gregor K. Wenning 2,4
}

\begin{abstract}
Cognitive dysfunction may occur in $17-40 \%$ of patients with multiple system atrophy (MSA). It has been suggested a milder cognitive impairment in cerebellar (MSA-C) than in parkinsonian variant (MSA-P). However, differences in cognitive profiles remain under discussion. Objective: To evaluate cognitive features in a series of patients with "probable MSA" from Argentina. Method: After informed consent was obtained, an extensive cognitive tests battery was administered. Nine patients (6 MSA-P and 3 MSA-C) composed the sample. Results: Depression was detected in $43 \%$ of patients. Seven patients showed at least one cognitive domain impairment. Temporospatial orientation, visuospatial abilities, executive and attentional functions, episodic memory and language were compromised in MSA-P, while MSA-C dysfunction was restricted to attentional and executive domains. Conclusion: Despite the small sample size, our findings could suggest a more widespread cognitive impairment in MSA-P than MSA-C.
\end{abstract}

Keywords: parkinsonism, multiple system atrophy, cognition.

\section{RESUMO}

Disfunção cognitiva pode ocorrer em 17-40 \% dos pacientes com atrofia de múltiplos sistemas (AMS). Alguns estudos têm sugerido a presença de disfunção cognitiva mais leve nos pacientes com AMS do tipo cerebelar (AMS-C) do que na variante parkinsoniana (AMS-P). Objetivo: Avaliar os perfis cognitivos de uma série de pacientes argentinos com "Provável AMS". Método: Foram selecionados 6 AMS-P e 3 AMS-C aos quais foi aplicada uma extensa bateria de testes cognitivos. Resultados: Depressão foi detectada em $43 \%$ dos pacientes. Sete pacientes apresentaram comprometimento de pelo menos um domínio cognitivo. As funções de orientação temporo-espacial, habilidades visuo-espaciais, função executiva e de atenção, memória episódica e linguagem foram comprometidas em pacientes com AMS-P. Nos pacientes com AMS-C as dificuldades cognitivas ficaram restritas às funções executivas e de atenção. Conclusão: Apesar do pequeno tamanho da amostra, nossos achados sugerem que pacientes com AMS-P apresentam um comprometimento cognitivo mais amplo do que pacientes com AMS-C.

Palavras-chave: parkinsonismo, atrofia de múltiplos sistemas, cognição.

Multiple system atrophy (MSA) is a rare, adult-onset, progressive neurodegenerative disease characterized by parkinsonism, cerebellar ataxia, corticospinal tract dysfunction and non-motor symptoms including autonomic failure, sleep disorders and respiratory manifestations. In 1998 Gilman et al. proposed the first consensus criteria diagnosis of $\mathrm{MSA}^{1}$, and a revised consensus was published in $2008^{2}$. Two clinical MSA categories can be distinguished: MSA-P with predominant parkinsonism and striatonigral involvement, and MSA-C dominated by cerebellar ataxia reflecting olivopontocerebellar involvement ${ }^{3}$.
A frontal-type cognitive impairment profile has been described in MSA patients ${ }^{4,5}$ and although dementia appears as a non-supportive feature of MSA, recent evidence suggests that cognitive dysfunction may be more frequent than previously reported, with a prevalence between $17-40 \%{ }^{6-8}$.

In some studies, patients with MSA-P have shown involvement of verbal retrieval and visuospatial and executive abilities, and patients with MSA-C have shown compromise in visuospatial functions, learning new verbal information, verbal fluency and attention tests ${ }^{6,9,10}$. It has been suggested that MSA-C patients may have a milder

${ }^{1}$ Department of Movement Disorders, Instituto Neurociencias de Buenos Aires (INEBA), Buenos Aires, Argentina;

${ }^{2}$ Sanatorio de la Trinidad Mitre, Buenos Aires, Argentina;

${ }^{3}$ Unit of Cognitive Neuroscience. Instituto Neurociencias de Buenos Aires (INEBA), Buenos Aires, Argentina;

${ }^{4}$ Division of Neurobiology Department of Neurology Medical University Innsbruck, Austria.

Correspondence: Emilia Mabel Gatto; Juramento, 1155 - 3A; CP 1428 Buenos Aires, Argentina; E-mail: emiliagatto@fibertel.com.ar

Conflict of interest: There is no conflict of interest to declare.

Received 13 May 2014; Received in final form 01 July 2014; Accepted 21 July 2014. 
degree of cognitive involvement compared with patients with MSA-P ${ }^{6}$. On the other hand, some studies did not find any differences in the cognitive performance between the 2 subtypes of MSA, with $41 \%$ of MSA patients showing frontal lobe-related function involvement ${ }^{8}$.

To the best of our knowledge, no data about MSA cognitive impairment are available from Latin America. The present study was conducted to assess cognitive and mood impairment in a series of MSA patients from Argentina.

\section{METHOD}

The study was approved by our institutional review board, and all participants signed a written informed consent in accordance with Good Clinical Practice guidelines and the Declaration of Helsinki. Patients fulfilling consensus criteria of clinical diagnosis of "probable MSA" composed the sample. Clinical evaluation of MSA patients included the Hoehn and Yahr (HY) scale.

An extensive neuropsychological test battery was administered that included: the Mini Mental State Examination (MMSE) as a global measure; the California Verbal Learning Test (CVLT) and the Wechsler Memory Scale to evaluate episodic memory; the Clock drawing Test and Block Design to evaluate visuospatial abilities; Direct and Inverse Span and Trail Making Test A (TMT A) to evaluate attentional functions; semantic fluency, phonological fluency and Boston Naming Test to evaluate language; and Trail Making Test B (TMT B) to evaluate executive functions. The results in each test were compared with normative data for age and education, and a $\mathrm{Z}$ score of less than 1.5 was considered abnormal. The Beck Inventory was selected to assess depressive symptoms, with a cut-off score of 9 for depression, and the Hospitality Anxiety and Depression scale - Anxiety (HAD-A) to assess anxiety symptoms, with a cut-off score of 8 for anxiety. Descriptive statistics were used to analyze the data. Statistical analysis was performed using the software program SPSS (Windows Release 11.0;
SPSS Inc, Chicago, Illinois), non-parametric tests (MannWhitney U test) were used when appropriate $(\mathrm{p} \leq 0.05)$.

\section{RESULTS}

The study population included 5 men and 4 women with probable MSA (6 MSA-P, 3 MSA-C) according to the revised consensus diagnostic criteria ${ }^{2}$. Socio-demographic data, MMSE, Beck Inventory and HAD-A results are shown in Table 1. When we compared MSA-C vs. MSA-P, we found no significant difference in disease duration and $\mathrm{HY}$ stage. The results on each cognitive test for the whole group and for each MSA subtype are shown in Table 2.

When considering the whole group, MSA patients demonstrated difficulties in the encoding of the CVLT and in TMT B (Table 2). At least one cognitive domain was impaired in $7 / 9$ of MSA patients (78\%), and 5 of them were of the MSA-P subtype. Impaired attention, executive dysfunction, and episodic memory dysfunction were present in $5 / 9(55 \%)$ patients each while visuospatial dysfunction $(3 / 9,33 \%)$, language alterations $(3 / 9,33 \%)$ and temporospatial dysfunction $(1 / 9,11 \%)$ were less prominent. In general, despite similar disease severity cognitive impairments were more widespread in MSA-P patients compared to MSA-C patients. Depression was identified in $3 / 7$ patients (43\%), while anxiety was observed in $1 / 7$ patients (14\%).

\section{DISCUSSION}

This is the first study to investigate cognitive function in patients with probable MSA from Argentina. As reported in the literature, cognitive dysfunction was frequent in this MSA sample. Episodic memory and attentional and executive deficits were the most prevalent cognitive alterations observed. Some of these cognitive abilities depend on prefrontal cortical areas and on their connections with frontal subcortical structures, which are usually involved in $\mathrm{MSA}^{11}$.

Table 1. Sociodemographic data, MMSE, beck inventory and HAD-A results.

\begin{tabular}{|c|c|c|c|c|c|c|c|c|c|c|}
\hline & \multicolumn{3}{|c|}{ MSA $(n=9)$} & \multicolumn{3}{|c|}{ MSA-P $(n=6)$} & \multicolumn{3}{|c|}{ MSA-C $(n=3)$} & \multirow{2}{*}{$\mathrm{p}$} \\
\hline & $\mathrm{M} / \mathrm{F}$ & Median & Range & $\mathrm{M} / \mathrm{F}$ & Median & Range & $\mathrm{M} / \mathrm{F}$ & Median & Range & \\
\hline Age (years) & & 66 & $56-77$ & & 68.5 & $63-77$ & & 57 & $56-64$ & \\
\hline Education (years) & & 13 & $7-18$ & & 12 & $7-17$ & & 17 & $16-18$ & \\
\hline Sex (male/female) & $5 / 4$ & & & $3 / 3$ & & & $2 / 1$ & & & \\
\hline Disease duration (years) & & 4 & $1-8$ & & 4 & $1-8$ & & 2 & $1-4$ & NS 0.548 \\
\hline Hoehn and Yahr & & 3 & $2-4$ & & 3 & $3-4$ & & 3 & $2-3$ & NS 0.262 \\
\hline MMSE & & 29 & $25-30$ & & 29 & $25-30$ & & 29 & $29-30$ & \\
\hline Beck inventory & & 9 & $3-21$ & & 9 & 3-12 & & 13 & $6-21$ & \\
\hline HAD-A & & 4 & $1-9$ & & 4 & $1-9$ & & 4 & $4-5$ & \\
\hline
\end{tabular}

M/F: male, female number; MSA: Multiple System Atrophy; P: Parkinsonism; C: Cerebellar; MMSE: Mini Mental State Examination; HAD-A: Hospitality Anxiety and Depression Scale - Anxiety. 
Table 2. Results on each cognitive test for the whole group and for each MSA subtype.

\begin{tabular}{|c|c|c|c|c|c|c|}
\hline & \multicolumn{2}{|c|}{ Total $(n=9)$} & \multicolumn{2}{|c|}{ MSA-P $(n=6)$} & \multicolumn{2}{|c|}{ MSA-C $(n=3)$} \\
\hline & Median & Range (Max;Min) & Median & Range (Max;Min) & Median & Range (Max;Min) \\
\hline WMS (immediate) & -0.08 & $(1.03 ;-2.59)$ & -0.41 & $(0.81 ;-2.59)$ & 1.03 & $(1.03 ;-0.08)$ \\
\hline WMS (delay) & 0.32 & $(1.48 ;-1.49)$ & -0.56 & $(0.52 ;-1.49)$ & 1.15 & $(1.48 ;-0.32)$ \\
\hline CVLT (encoding) & -1.67 & $(0.23 ;-2.93)$ & -1.92 & $(-1.18 ;-2.93)$ & -0.35 & $(0.23 ;-0.42)$ \\
\hline CVLT (immediate) & -1.18 & $(0.28 ;-2.73)$ & -1.50 & $(-1.14 ;-2.73)$ & -0.85 & $(0.28 ;-0.90)$ \\
\hline CVLT (delay) & -0.64 & $(0.53 ;-2.60)$ & -1.32 & $(-0.61 ;-2.60)$ & 0.26 & $(0.53 ;-0.27)$ \\
\hline BNT & -1.14 & $(1.47,-2.29)$ & -0.79 & $(1.47 ;-2.29)$ & -1.18 & $(-0.53 ;-1.32)$ \\
\hline Semantic fluency & -1.04 & $(0.27 ;-2.90)$ & -0.94 & $(0.27 ;-2.90)$ & -1.04 & $(-0.08 ;-1.41)$ \\
\hline Phonological fluency & -1.00 & $(0.22 ;-1.86)$ & -1.10 & $(0.13 ;-1.86)$ & 0.12 & $(0.22 ;-1.13)$ \\
\hline Block design & -0.50 & $(0.33 ;-2.33)$ & -0.83 & $(0.19 ;-2.33)$ & -0.17 & $(0.33 ;-0.67)$ \\
\hline Direct span & 1.89 & $(5.00 ;-0.57)$ & 1.61 & $(5.00 ;-0.57)$ & 2.36 & $(2.44 ;-0.36)$ \\
\hline Inverse span & 1.55 & $(2.89 ;-2.56)$ & 1.09 & $(2.89 ;-2.56)$ & 1.56 & $(2.45 ; 1.55)$ \\
\hline TMTA & -1.33 & $(-0,67 ;-2.67)$ & -1.33 & $(-0.67 ;-2.67)$ & -2.00 & $(-1.00 ;-2.07)$ \\
\hline TMTB & -1.67 & $(0.00 ;-5.35)$ & -1.67 & $(-0.67 ;-2.67)$ & -1.67 & $(0.00 ;-5.35)$ \\
\hline
\end{tabular}

WMS: Wechsler Memory Scale; CVLT: California Verbal Learning Test; BNT: Boston Naming Test; TMT: Trail Making Test.

Temporospatial disorientation, episodic memory and visuospatial and language dysfunctions were exclusively identified in patients with the MSA-P variant. Interestingly, some of these cognitive alterations may not be identified with global cognitive screening tests such as the MMSE: in this sample the median of the MMSE score was 29, ranging from 25 to 30 .

In agreement with previous reports, mild to moderate deficits in executive functions and impairment in attention and phonological fluency were observed in this population $^{12,13}$.

Although the occurrence of different cognitive patterns between both subtypes of MSA remains under discussion ${ }^{6,8}$, in this sample we identified a more widespread cognitive dysfunction in MSA-P with respect to MSA-C. In fact, cognitive performance in MSA-P was compromised in multiple cognitive domains (temporospatial orientation, visuospatial abilities, executive and attentional functions, episodic memory and language), while in MSA-C, the cognitive dysfunction was restricted to attentional and executive deficits (frontal-executive disorder). However, these results must be analyzed cautiously, considering the sample size. Nevertheless, cognitive impairment observed in MSA-P could contribute to support the hypothesis of an earlier basal ganglia neuronal dysfunction in this clinical variant. Moreover the lack of differences in disease severity as determined by HY stage would support more widespread P type related cognitive deficits, despite the caution of very few cases only.
On the other hand, it has been reported that MSA patients may have more depression than patients with $\mathrm{PD}^{8,12}$. In this sample, Beck inventory showed significant depressive symptoms in more than $40 \%$ of the patients that were evaluated, while anxiety symptoms were only significant in one patient. Depression tended to be more severely in patients with MSA-C, probably reflecting a cerebellocortical circuits involvement.

The limitations of the present study included, the absence of epidemiological or demographic data of MSA from Latin America and more specifically from Argentina, the lack of neuropathological confirmation and the small number of patients. However, the presence of cognitive dysfunction in at least one cognitive domain appears to be in accordance with other international series and contribute to support the cognitive impairment in MSA.

In conclusion, patients with MSA showed cognitive impairment in different sub-domains, with a more widespread impairment in MSA-P than MSA-C. Extensive studies are required to identify the anatomical correlation or risk factor specific to each subtype. A larger scale population study is ongoing.

\section{Acknowledgments}

Authors would like to thank all patients, their families, and the Neuropsychologists of Instituto de Neurociencias Buenos Aires (INEBA) who evaluated our patients.

\section{References}

1. Gilman S, Low P, Quinn N, Albanese A, Ben-Shlomo Y, Fowler C et al. Consensus statement on the diagnosis of multiple system atrophy. J Neurol Sci. 1999;163(1):94-8. http://dx.doi.org/10.1016/S0022-510X (98)00304-9
2. Gilman S, Wenning GK, Low PA, Brooks DJ, Mathias CJ, Trojanowski $J Q$ et al. Second consensus statement on the diagnosis of multiple system atrophy. Neurology. 2008;71(9):670-6. http://dx.doi. org/10.1212/01.wnl.0000324625.00404.15 
3. Wenning GK, Stefanova N. Recent developments in multiple system atrophy. J Neurol. 2009;246(11):1791-808. http://dx.doi.org/10.1007/ s00415-009-5173-8

4. Robbins TW, James M, Lange KW, Owen AM, Quinn NP, Marsden CD. Cognitive performance in multiple system atrophy. Brain. 1992;115(1):271-91. http://dx.doi.org/10.1093/brain/115.1.271

5. Berent S, Giordani B, Gilman S, Trask CL, Little RJ, Johanns JR et al. Patterns of neuropsychological performance in multiple system atrophy compared to sporadic and hereditary olivopontocerebellar atrophy. Brain Cogn. 2002;50(2):194-206. http://dx.doi.org/10.1016/ s0278-2626(02)00503-1

6. Kawai Y, Suenaga M, Takeda A, Ito M, Watanabe H, Tanaka H et al. Cognitive impairments in multiple system atrophy: MSA-C vs MSA-P. Neurology. 2008;70(16 Pt 2):1390-6. http://dx.doi.org/10.1212/01. wnl.0000310413.04462.6a

7. Brown RG, Lacomblez L, Landwehrmeyer BG, Bak T, Uttner I, Dubois B et al. Cognitive impairment in patients with multiple system atrophy and progressive supranuclear palsy. Brain. 2010;133(8):2382-93. http://dx.doi.org/10.1093/brain/awq158

8. Siri C, Duerr S, Canesi M, Delazer M, Esselink R, Bloem BR et al. A cross-sectional multicenter study of cognitive and behavioural features in multiple system atrophy patients of the parkinsonian and cerebellar type. J Neural Transm. 2013;120(4):613-8. http://dx. doi.org/10.1007/s00702-013-0997-x

9. Balas M, Balash Y, Giladi N, Gurevich T. Cognition in multiple system atrophy: neuropsychological profile and interaction with mood. J Neural Transm. 2010;117(3):369-75. http://dx.doi.org/10.1007/ s00702-009-0365-z

10. Bürk K, Daum I, Rüb U. Cognitive function in multiple system atrophy of the cerebellar type. Mov Disord. 2006;21(6):772-6. http://dx.doi. org/10.1002/mds.20802

11. Chang CC, Chang YY, Chang WN, Lee YC, Wang YL, Lui CC et al. Cognitive deficits in multiple system atrophy correlate with frontal atrophy and disease duration. Eur J Neurol. 2009;16(10):1144-50. http://dx.doi.org/10.1111/j.1468-1331.2009.02661.x

12. Soliveri P, Monza D, Paridi D, et al. Neuropsychological follow up in patients with Parkinson's disease, striatonigral degeneration-type multisystem atrophy, and progressive supranuclear palsy. J Neurol Neurosurg Psychiatry. 2000;69(3):313-8. http://dx.doi.org/10.1136/ jnnp.69.3.313

13. Spaccavento S, Del Prete M, Loverre A, Craca A, Nardulli R. Multiple system atrophy with early cognitive deficits: a case report. Neurocase. 2013;19(6):613-22. http://dx.doi.org/10.1080/13554794. 2012.713494 